\title{
Effect of immobilization of titanocene catalyst in aralkyl imidazolium chloroaluminate media on performance of biphasic ethylene polymerization and polyethylene properties
}

\author{
Wioletta Ochędzan-Siodłak • Katarzyna Dziubek • \\ Krystyna Czaja
}

Received: 2 May 2012/Revised: 28 June 2012 / Accepted: 6 July 2012 /

Published online: 15 July 2012

(C) The Author(s) 2012. This article is published with open access at Springerlink.com

\begin{abstract}
Phenylethyl)-3-methylimidazolium and 1-benzyl-3-methylimidazolium chloroaluminates, $\left[\mathrm{Ph}-\mathrm{C}_{2} \mathrm{mim}\right]\left[\mathrm{AlCl}_{4}\right]$ and $[\mathrm{Bzlmim}]\left[\mathrm{AlCl}_{4}\right]$, were applied as media of the $\mathrm{Cp}_{2} \mathrm{TiCl}_{2}$ catalyst for biphasic ethylene polymerization. The studied aralkyl ionic liquids ensure greater stability of the catalyst at higher temperatures and more regular morphology of the produced polyethylene than analogous 1-n-alkyl-3methylimidazolium chloroaluminates. The alkylaluminium compound participates in the termination reaction of the polymer chain. The catalyst is stable and enables recycling of the ionic liquid phase in the consecutive polymerization reactions. The $\left[\mathrm{Ph}-\mathrm{C}_{2} \mathrm{mim}\right]\left[\mathrm{AlCl}_{4}\right]$ ionic liquid and $\mathrm{AlEt}_{2} \mathrm{Cl}$ alkylaluminium compound turned out to be the most suitable for the biphasic process. The influence of the kind of ionic liquid, alkylaluminium compound $\left(\mathrm{AlEt}_{2} \mathrm{Cl}\right.$ and $\left.\mathrm{AlEtCl}_{2}\right)$, activator/catalyst molar ratio, reaction temperature, reaction time and catalyst recycling on the polymerization performance as well as polyethylene properties such as molecular weight $\left(M_{w}\right)$, polydispersity, melting temperature, crystallinity degree, bulk density and particle size is presented.
\end{abstract}

Keywords Polyethylene $\cdot$ Ionic liquid $\cdot$ Metallocene catalyst

\section{Introduction}

Metallocenes are a consecutive generation of organometallic catalysts for olefin polymerization, which make possible to tailor the structure of polymers in a way which has not been achieved before [1-5]. Unfortunately, the metallocene systems, both homogeneous and heterogeneous, have disadvantageous features hindering their application in industrial scale processes [6-8]. Therefore, there is a need to

W. Ochędzan-Siodłak $(\bowtie) \cdot$ K. Dziubek $\cdot$ K. Czaja

Faculty of Chemistry, Opole University, Oleska 48, 45-052 Opole, Poland

e-mail:wsiodlak@uni.opole.pl 
search for new methods of the olefin polymerization using the metallocene catalysts, but deprived of toxic solvents (toluene, xylene), great excess of activator methylaluminoxane (MAO) [9] and multi-step anchorage of the metallocene on a solid support [6-9]. An innovative method for the olefin polymerization can be liquid-liquid biphasic system. Advantageous features of this method are mild reaction conditions, facile product separation and recycling of the catalyst system [10-12].

Promising possibility to immobilize organometallic catalysts in a separate phase create ionic liquids, which have recently attracted attention as an environment friendly, reusable media for organic synthesis, and thus becoming an alternative to common solvents $[11,13,14]$. A unique feature of the ionic liquids is the possibility to design their chemical and physical properties for specific applications through the choice of the cation and anion. This makes it possible to control, for example, melting temperature, density, viscosity and miscibility with other solvents [13-19]. Fine tuning of the properties can also be performed by changing the substituents at the ionic liquid cation [13, 14, 18]. Recently, task-specific ionic liquids, which contain various functional groups in the cation side chain, have attracted considerable interest [14, 20-22]. Modifying the ionic liquids structure results in a change of their properties, which enables them to be applied to many types of reactions [13, 14, 23-27]. Therefore, application of the ionic liquid as a medium of metallocene catalyst gives possibility to control the morphology of the polymer not only by the catalyst structure but also by the proper choice of the catalyst phase.

Our previous investigations proved a utility of the chloroaluminate ionic liquids in the biphasic ionic liquid/hexane ethylene polymerization using the titanocene catalyst $\left(\mathrm{Cp}_{2} \mathrm{TiCl}_{2}\right)$ avoiding the application $\mathrm{MAO}$ as the activator [28-32]. It was found that even a small change in the structure of the studied ionic liquids, 1-n-alkyl-3-methylimidazolium and 1-n-alkyl 4-methylpyridinium chloroalumiantes, i.e. in the length of the alkyl chain at the aromatic cation, influences the performance of the polymerization process and the properties of the polyethylene product such as melting temperature, crystallity degree, molecular weight $\left(M_{w}\right)$, molecular weight distribution $\left(M_{w} / M_{n}\right)$ and bulk density [30-32]. Despite of the promising results obtained, further studies need to be continued to improve the biphasic process, i.e. the mass transfer between the phases, phases separation, catalyst activity and properties of the polymer product. A rational method is modification of the ionic liquid phase by searching for suitable ionic liquid structure.

Recently, the most applied method of modification of the cation structure is introduction of various functional groups, e.g. $-\mathrm{CN},-\mathrm{OH},-\mathrm{OR},-\mathrm{SH},-\mathrm{SO}_{3} \mathrm{H}$, $-\mathrm{COOH}[20,21,33,34]$. Unfortunately, these groups cannot be applied in the case of metallocene catalysts because they deactivate the catalyst active sites. Furthermore, such functionalities react with chloroaluminate compounds which are necessary to create the metallocene active centres, and thus cannot be applied for design of the chloroaluminate ionic liquids. However, aromatic function at the side chain seems to be interesting options. Many polymerization reactions using the metallocene catalysts are performed in the aromatic toluene [35, 36]. The metallocene catalyst, alkylaluminium activators and $\alpha$-olefins substrates show good 


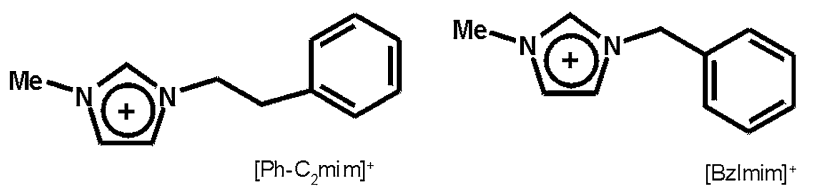

Fig. 1 Imidazolium cations with aralkyl substituents of the chloroaluminate ionic liquids studied in this work

solubility in aromatic environment, which improves performance of the polymerization reaction. Unfortunately, aromatic solvents are partially miscible with the ionic liquids and their application in the biphasic process makes the phase separation, and thus, product separation very difficult.

The application of the aralkyl ionic liquid having aromatic functionality at the cation side chain can be interesting solution, worth to study. Based on the recent report [37], it can be assumed that aromatic functionality, through a donor-acceptor interaction with alkylaluminium activators, can influence acidity of the chloroaluminate ionic liquids as well as the creation of the active centres. On the other hand, the aralkyl ionic liquid is immiscible with hexane and thus the catalyst recycling would be possible, which is very important feature of the biphasic processes [38].

In this study, we focused on the ethylene polymerization reaction carried out in the biphasic ionic liquid/hexane process, where the metallocene catalyst $\left(\mathrm{Cp}_{2} \mathrm{TiCl}_{2}\right)$ as well as the activator $\left(\mathrm{AlEt}_{2} \mathrm{Cl}\right.$ and $\left.\mathrm{AlEtCl}_{2}\right)$ were dissolved in the aralkyl chloroaluminate ionic liquids where aralkyl substituents, 1-(2-phenylethyl) and benzyl, are present at the imidazolium cation (Fig. 1). This kind of ionic liquids has not been investigated to date in oligomerization and polymerization reactions. So far, these ionic liquids were applied in separating $\mathrm{CO}_{2}$ and $\mathrm{N}_{2}[39,40]$. However, they reveal greater thermal stability than analogues with alkyl side chain [40]. It should be noted that the ionic liquids with an aralkyl substituent could potentially be suitable for the heterogenization of an organometallic catalyst on a solid carrier in the supported ionic liquids phase (SILP) method, which appears to be an another promising method for the catalyst immobilization [41, 42].

\section{Experimental}

\section{Materials}

Ethylene (Linde AG Gaz) and pure nitrogen (Polgaz) were used after having been passed through a column of sodium metal supported on $\mathrm{Al}_{2} \mathrm{O}_{3}$. Pure-grade hexane (POCH, Gliwice) was refined with sulphuric acid and sodium hydroxide, distilled to gain a fraction $\left(62-67{ }^{\circ} \mathrm{C}\right)$ and distilled again with sodium/benzophenone, and stored with sodium metal. 1,2,4-Trichlorobenzene (TCB, 99 wt \%) (Aldrich) was purified by distillation. $o$-Dichlorobenzene- $\mathrm{d}_{4}$ (Chemat) was applied as purchased. Diethyl ether $\left[\left(\mathrm{C}_{2} \mathrm{H}_{5}\right)_{2} \mathrm{O}, \mathrm{POCH}\right.$, Gliwice] was distilled with metallic sodium. Acetonitryle $\left(\mathrm{CH}_{3} \mathrm{CN}\right.$, POCH, Gliwice $)$ and ethyl acetate $\left(\mathrm{CH}_{3} \mathrm{COOC}_{2} \mathrm{H}_{5}, \mathrm{POCH}\right.$, Gliwice) were stored using molecular sieves. 1-Methylimidazole $\left(\mathrm{C}_{4} \mathrm{H}_{6} \mathrm{~N}_{2}\right.$, 
Aldrich), benzyl chloride $\left(\mathrm{C}_{7} \mathrm{H}_{7} \mathrm{Cl}\right.$, Sigma), bis(cyclopentadienyl)titanium(IV) dichloride $\left(\mathrm{Cp}_{2} \mathrm{TiCl}_{2}\right.$, Aldrich), ethylaluminium dichloride $\left(\mathrm{AlEtCl}_{2}, 1 \mathrm{M}\right.$ as hexane solution Aldrich), diethylaluminium chloride $\left(\mathrm{AlEt}_{2} \mathrm{Cl}, 1 \mathrm{M}\right.$ as hexane solution Aldrich) and aluminium chloride $\left(\mathrm{AlCl}_{3}\right.$, Aldrich) were applied as purchased.

Synthesis of the 1-(2-phenylethyl)-3-methylimidazolium chloroaluminate

All steps were carried out in water- and oxygen-free conditions using an inert nitrogen atmosphere. 2-Chloroethylbenzene $(0.4 \mathrm{~mol})$ was dropped into methylimidazole $(0.4 \mathrm{~mol})$. The light-brown mixture was stirred for $1 \mathrm{~h}$ at $90{ }^{\circ} \mathrm{C}$. The crude 1-(2-phenylethyl)-3-methylimidazolium chloride, $\left[\mathrm{Ph}-\mathrm{C}_{2} \mathrm{mim}\right] \mathrm{Cl}$, in the form of a light-brown viscous oil, was cooled to room temperature and washed using $30 \mathrm{~cm}^{3}$ diethyl ether and left to stand to crystallize. It was further purified by diethyl ether $\left(4 \times 30 \mathrm{~cm}^{3}\right)$ and hexane $\left(4 \times 50 \mathrm{~cm}^{3}\right)$ in a Schlenk apparatus. The product obtained was in the form of an off-white powder with $80 \%$ yield. ${ }^{1} \mathrm{H} \mathrm{NMR}\left(\mathrm{CDCl}_{3}\right)$ $\delta 10.62(1 \mathrm{H}, \mathrm{s}), 7.42(1 \mathrm{H}, \mathrm{t}, J=1.8 \mathrm{~Hz}), 7.31-7.18(6 \mathrm{H}, \mathrm{m}), 4.63(2 \mathrm{H}, \mathrm{t}$, $J=7.4 \mathrm{~Hz}), 4.04(3 \mathrm{H}, \mathrm{s}), 3.24(2 \mathrm{H}, 7, J=7.4 \mathrm{~Hz}) ;{ }^{13} \mathrm{C} \mathrm{NMR}\left(\mathrm{CDCl}_{3}\right) \delta 138.2(\mathrm{~s})$, 135.9 (s), 129.0 (s), 128.9 (s), 127.5 (s), 123.0 (s), 122.3 (s), 51.1 (s), 36.6 (s), 36.6 (s). Elemental analysis (\%) for $\mathrm{C}_{12} \mathrm{H}_{15} \mathrm{ClN}_{2}$ (222.72); calcd: $\mathrm{C} 64.72, \mathrm{H} 6.79, \mathrm{~N}$ 12.58; found: C 64.47, H 6.88, N 12.48. FT-IR (KBr) $v=3141,3061,2857,1572$, 1455, 1167, 1084, 856, 755, 703, $622 \mathrm{~cm}^{-1}$.

To the obtained $\left[\mathrm{Ph}-\mathrm{C}_{2} \mathrm{mim}\right] \mathrm{Cl}$, an equivalent amount of aluminium chloride was added slowly while the mixture was stirred continually. The obtained 1-(2-phenylethyl)3-methylimidazolium chloroaluminate, which was liquid during synthesis, crystallized in the form of a light-orange solid.

\section{Synthesis of the 1-benzyl-3-methylimidazolium chloroaluminate}

All steps were carried out in water- and oxygen-free conditions using an inert nitrogen atmosphere. Benzyl chloride $(0.4 \mathrm{~mol})$ was dropped into methylimidazole $(0.4 \mathrm{~mol})$. The mixture was stirred for $5 \mathrm{~h}$ at $70-110^{\circ} \mathrm{C}$. The obtained crude 1-benzyl-3-methylimidazolium chloride, [Bzlmim] $\mathrm{Cl}$, in the form of a light-orange viscous oil was dissolved in $70 \mathrm{~cm}^{3}$ acetonitrile and washed with diethyl ether $\left(3 \times 40 \mathrm{~cm}^{3}\right)$, ethyl acetate $\left(4 \times 20 \mathrm{~cm}^{3}\right)$ and again with diethyl ether $\left(4 \times 50 \mathrm{~cm}^{3}\right)$, and finally with hexane $\left(4 \times 50 \mathrm{~cm}^{3}\right)$. The product was left to stand over the hexane phase overnight to crystallize. The solid form was dried by nitrogen flow in a Schlenk apparatus to reach a constant weight. The product was obtained in the form of an off-white powder with $78 \%$ yield. ${ }^{1} \mathrm{H}$ NMR $\left(\mathrm{CDCl}_{3}\right) \delta 10.84(1 \mathrm{H}, \mathrm{s}), 7.51$ $(1 \mathrm{H}, \mathrm{s}), 7.49-7.47(2 \mathrm{H}, \mathrm{m}), 7.38-7.36(4 \mathrm{H}, \mathrm{m}), 5.59(2 \mathrm{H}, \mathrm{s}), 4.07(3 \mathrm{H}, \mathrm{s}) ;{ }^{13} \mathrm{C} \mathrm{NMR}$ $\left(\mathrm{CDCl}_{3}\right) \delta 138.1$ (s), 133.2 (s), 129.5 (s), 129.4 (s), 129.0 (s), 123.6 (s), 121.8 (s), 53.3 (s), 36.7 (s). Elemental analysis (\%) for $\mathrm{C}_{11} \mathrm{H}_{13} \mathrm{ClN}_{2}$ (208.69); calcd: C 63.31, H 6.28, N 13.42; found: C 63.45, H 6.26, N 13.71. FT-IR (KBr) $v=3136,3062$, $2853,1571,1456,1162,1083,856,723,699,623 \mathrm{~cm}^{-1}$.

To the obtained [Bzlmim]Cl, an equivalent amount of aluminium chloride was added slowly while the mixture was stirred constantly. The obtained 1-benzyl-3- 
methylimidazolium chloroaluminate, liquid during synthesis, crystallized in the form of an off-white solid.

\section{Biphasic polymerization of ethylene}

All steps were carried out in water- and oxygen-free conditions using an inert nitrogen atmosphere. The studied aralkyl imidazolium chloroaluminates $\left(5 \mathrm{~cm}^{3}\right)$, warmed to obtain their liquid forms (c.a. $40{ }^{\circ} \mathrm{C}$ ), was added to the alkylaluminium compound. The mixture was stirred for $0.5 \mathrm{~h}$ and left to stand overnight. Then, it was warmed to the required temperature $\left(42-50{ }^{\circ} \mathrm{C}\right)$ and the catalyst was added shortly before it was applied to the polymerization reaction. To investigate the influence of the activator/catalyst molar ratio on the performance of the polymerization reaction, the amount of the alkylaluminium compound $\left(\mathrm{AlEtCl}_{2}\right.$ or $\left.\mathrm{AlEt}_{2} \mathrm{Cl}\right)$ was gradually changed $\left(2.0-6.0 \times 10^{-3} \mathrm{~mol}\right)$ while the amount of the $\mathrm{Cp}_{2} \mathrm{TiCl}_{2}$ catalyst $\left(3.0 \times 10^{-5} \mathrm{~mol}\right.$ of $\left.\mathrm{Ti}\right)$ was kept constant. The polymerization reaction was conducted in a $500-\mathrm{cm}^{3}$ glass reactor equipped with a mechanical stirrer and a water jacket to maintain a constant temperature. In the biphasic system applied, the ionic liquid constitutes the bottom phase, in which the catalyst and activator were dissolved. The upper phase $\left(150 \mathrm{~cm}^{3}\right)$ was hexane containing an alkylaluminium compound $\left(2.0 \times 10^{-4} \mathrm{~mol}\right.$ of $\left.\mathrm{Al}\right)$ to act as a scavenger of impurities. Hexane and the previously prepared mixture of the ionic liquid/ alkylaluminium compound containing $\mathrm{Cp}_{2} \mathrm{TiCl}_{2}$ were added successively into the reactor under a nitrogen atmosphere. The ethylene was bubbled through the ionic liquid phase at a pressure of $0.5 \mathrm{MPa}$, while the temperature was maintained at $42-50{ }^{\circ} \mathrm{C}$. The polymerization reaction was terminated by the closure of the ethylene feed. The hexane phase was decanted. The polyethylene from both phases was filtered off, washed by $5 \% \mathrm{HCl}$ methanolic solution, methanol, and dried to obtain a white powder for the hexane phase.

\section{Catalyst leaking}

The $[\mathrm{Bzlmim}]\left[\mathrm{AlCl}_{4}\right]$ and $\left[\mathrm{Ph}-\mathrm{C}_{2} \mathrm{mim}\right]\left[\mathrm{AlCl}_{4}\right]$ ionic liquids contained the $\mathrm{Cp}_{2} \mathrm{TiCl}_{2}$ $\left(3.0 \times 10^{-5} \mathrm{~mol}\right.$ of $\left.\mathrm{Ti}\right)$ catalyst and the alkylaluminium compound $\left(\mathrm{AlEt}_{2} \mathrm{Cl}\right.$ or $\left.\mathrm{AlEtCl}_{2}\right)\left(4.0 \times 10^{-3} \mathrm{~mol}\right.$ of $\left.\mathrm{Al}\right)$ were mixed with hexane under a nitrogen atmosphere for $1 \mathrm{~h}$ at $45{ }^{\circ} \mathrm{C}$. After the layers had settled, the ionic liquid was discarded and the hexane phase was taken into the ethylene flush at typical polymerization conditions $\left(0.5 \mathrm{MPa}, 45{ }^{\circ} \mathrm{C}, 60 \mathrm{~min}\right.$.). The hexane mixed over both aralkyl ionic liquids maintained transparent and no polyethylene was obtained. The absence of $\mathrm{Ti}$ in the hexane phase was also confirmed by atomic absorption spectrometry (AAS).

\section{Catalyst recycling in biphasic system}

The reaction was generally carried out according to the procedure described above. However, after $1 \mathrm{~h}$ of the first cycle, the polymerization was terminated by the closure of the ethylene feeding and the pressure was decreased to the standard 
conditions. In inert nitrogen conditions, free of oxygen and water, the hexane phase was removed by decantation while the ionic liquid phase containing the catalyst remained in the reactor. The second reaction cycle was performed introducing a new portion hexane $\left(150 \mathrm{~cm}^{3}\right)$ containing a small amount of the alkylaluminium compound $\left(2.0 \times 10^{-4} \mathrm{~mol}\right.$ of $\left.\mathrm{Al}\right)$ to reactor in order to act as a scavenger of impurities. The same procedure was repeated in the third cycle. Each cycle of the polymerization reaction was carried out in the same conditions (temperature: $45^{\circ} \mathrm{C}$, pressure of ethylene: $0.5 \mathrm{MPa}$, time reaction: $1 \mathrm{~h}$ ).

\section{Monophasic (homogeneous) polymerization of ethylene}

The polymerization was carried out in $500-\mathrm{cm}^{3}$ glass reactor equipped with a mechanical stirrer and a water jacket to maintain a constant temperature in waterand oxygen-free conditions using an inert nitrogen atmosphere. The hexane phase $\left(150 \mathrm{~cm}^{3}\right)$ containing an alkylaluminium compound $\left(2.0 \times 10^{-4} \mathrm{~mol}\right.$ of $\left.\mathrm{Al}\right)$ as a scavenger of impurities was placed in the reactor and warmed to $45^{\circ} \mathrm{C}$. The proper amount of the alkylaluminium compound $\left(\mathrm{AlEtCl}_{2}\right.$ or $\left.\mathrm{AlEt}_{2} \mathrm{Cl}\right)\left(2.0-4.0 \times 10^{-3}\right.$ mol of $\mathrm{Al})$ and the $\mathrm{Cp}_{2} \mathrm{TiCl}_{2}$ titanocene catalyst $\left(3.0 \times 10^{-5} \mathrm{~mol}\right.$ of $\left.\mathrm{Ti}\right)$ as toluene solution $\left(2 \mathrm{~cm}^{3}\right)$ were added. The polymerization reaction was started by ethylene feeding. The process was carried out at pressure $0.5 \mathrm{MPa}$, temperature $45^{\circ} \mathrm{C}$, during $1 \mathrm{~h}$. The polymerization reaction was terminated by the closure of the ethylene feed. The hexane phase was decanted. The polyethylene was filtered off, washed by $5 \% \mathrm{HCl}$ methanolic solution, methanol and dried to obtain a white powder.

\section{Instruments}

The FT-IR analysis was accomplished using a Nicole Nexus 2002 FT-IR spectrometer from 4,000 to $400 \mathrm{~cm}^{-1}$ with a $2 \mathrm{~cm}^{-1}$ resolution. The FT-IR analysis of the ionic liquids was investigated in Nujol $\mathrm{KBr} / \mathrm{KBr}$. The polymer samples were prepared in the form of tablets made of polymer powder and $\mathrm{KBr}$. The numbers of methyl $\left(-\mathrm{CH}_{3}\right)$ groups were estimated from the ratio of the absorption band with the maximum at $1379.3 \mathrm{~cm}^{-1}$ to the absorption of the band at $1368.7 \mathrm{~cm}^{-1}$ for the methylene $\left(-\mathrm{CH}_{2}-\right)$ groups.

The NMR spectra were recorded on a Bruker Ultrashield spectrometer (400 MHz). The number of branches and the kinds of the terminal groups of the polymer chain of the selected polyethylene samples were confirmed by ${ }^{1} \mathrm{H}$ NMR (o-dichlorobenzene- $\left.\mathrm{d}_{4}\right)$. The number of branches was found from the ratio of integrals of signals of the methyl groups $(0.86 \mathrm{ppm})$ to methylene groups $(1.30 \mathrm{ppm})$.

The amount of Ti in the hexane phase was measured by an AAS Unicam SOLAR 969.

The molecular weight and molecular weight distribution of each polymer sample were determined by gel permeation chromatography (Waters Alliance GPCV 2000) using TCB as the solvent at $142{ }^{\circ} \mathrm{C}$. The data were analysed using polystyrene calibration curves. 
The crystallinity and the melting temperature of the polyethylene were estimated with a DSC 2010 TA Instruments. The polymer crystallinity was calculated using the equation: $C=\left(\Delta H_{\mathrm{f}} / \Delta H_{\mathrm{t}, \mathrm{c}}\right) \times 100 \%$ where $\Delta H_{\mathrm{f}}$ is heat of fusion of the polyethylene sample, $\Delta H_{\mathrm{t}, \mathrm{c}}$ is the heat of fusion of standard which equals $290 \mathrm{~J} / \mathrm{g}$ and $C$ is crystallinity, (\%).

The bulk densities were measured according to ASTM Standard D 1895.

Viscosities of the ionic liquids were performed using a Brookfield model Alpha L (FungiLab) equipped with a small sample adapter (APM) with a thermostatic jacket. The ionic liquid samples were analysed in a temperature range $42-55^{\circ} \mathrm{C}$, in inert atmosphere (glove-box, nitrogen flow), using TL5-type spindle at $50 \mathrm{rpm}$.

Density for the ionic liquids was measured using the pycnometer method with distilled water as the reference immersion liquid.

Scanning electron microscope (SEM) experiment of the polyethylene samples was carried out on a Hitachi model TM 3000 electron microscope. The samples were fixed on an aluminium sample stub and coated with gold by conventional sputtering techniques. The employed accelerating voltage was 5-15 kV for SEM.

\section{Results and discussion}

\section{Polymerization reaction}

The ethylene polymerization was carried out in the biphasic ionic liquid/hexane process, where 1-benzyl-3-methylimidazolium [Bzlmim][ $\left.\mathrm{AlCl}_{4}\right]$ or 1-(2-phenylethyl)3-methylimidazolium $\left[\mathrm{Ph}-\mathrm{C}_{2} \mathrm{mim}\right]\left[\mathrm{AlCl}_{4}\right]$ chloroaluminates was applied as the medium of the $\mathrm{Cp}_{2} \mathrm{TiCl}_{2}$ catalyst activated by $\mathrm{AlEtCl}_{2}$ or $\mathrm{AlEt}_{2} \mathrm{Cl}$ alkylaluminium compounds. At the beginning of the polymerization reaction, regardless of the ionic liquid, activator or activator/catalyst molar ratio used, the polyethylene product first appears in the ionic liquid phase, which whitens and swells considerably. After about 5 min of the reaction, the hexane phase becomes a white suspension as the polyethylene is progressively shifted from the ionic liquid phase.

The concept of biphasic catalysis assumes that both catalyst and activator remain in the ionic liquid phase. The catalyst leaking should result in presence of the active sites in the hexane phase. Such phenomenon was not observed, which was confirmed by the experiment (see "Experimental" section) and AAS methods. It proves that the polymerization reaction takes place in the ionic liquid phase, which contains firmly immobilized catalyst.

Effects of the kind of ionic liquid, the alkylaluminium compound and the reaction temperature

Figures 2 and 3 present the influence of the ionic liquid, temperature and alkylaluminium compound on the catalyst activity. The studied ionic liquids with the aralkyl substituent at the imidazolium cation are solid at room temperature. The reaction cannot be carried out below $40{ }^{\circ} \mathrm{C}$. On the other hand, regardless of the ionic liquid studied, temperature higher than $50{ }^{\circ} \mathrm{C}$ causes deactivation of the 
titanocene catalyst and a decrease of the catalyst activity [43, 44]. Thus, the range of temperatures, in which the studied ionic liquid can be applied, equals $42-50{ }^{\circ} \mathrm{C}$. In the case of analogues with alkyl side chain, the optimal temperature was about $30{ }^{\circ} \mathrm{C}$, and at $40{ }^{\circ} \mathrm{C}$, a considerable decrease of the catalyst activity was observed. It should be noticed that the studied aralkyl ionic liquids enable to perform the polymerization at higher temperatures.

The type of ionic liquid impacts on the polymerization performance. This can particularly be seen for $\left[\mathrm{Ph}-\mathrm{C}_{2} \mathrm{mim}\right]\left[\mathrm{AlCl}_{4}\right]$, where even a small change in temperature has a considerable influence on the catalyst activity. For [Bzlmim] $\left[\mathrm{AlCl}_{4}\right]$, moderate changes can be observed. The optimal temperature depends on the ionic liquid-it is slightly higher for $[\mathrm{Bzlmim}]\left[\mathrm{AlCl}_{4}\right]\left(48{ }^{\circ} \mathrm{C}\right)$ than for $\left[\mathrm{Ph}-\mathrm{C}_{2} \mathrm{mim}\right]\left[\mathrm{AlCl}_{4}\right]\left(45^{\circ} \mathrm{C}\right)$. Regardless of the temperature and activator, better results were obtained for $[\mathrm{Ph}-$ $\left.\mathrm{C}_{2} \mathrm{mim}\right]\left[\mathrm{AlCl}_{4}\right]$ than for $[\mathrm{Bzlmim}]\left[\mathrm{AlCl}_{4}\right]$, although these two ionic liquids differ by merely the single methylene group at the side chain. These results confirm how relatively small changes of the substituent of the ionic liquid cation can influence the performance of the polymerization reaction.

As can be seen in both Figs. 2 and 3, for many polymerization reactions, the product remains in the ionic liquid phase. It is known that the usual high viscosity of the ionic liquids has considerable influence on the mass transfer, and thus limits their application as a medium of catalysts [12]. On the other hand, density of the ionic liquids influences dispersion of the ionic liquid phase in the hexane phase. Figure 4 and Table 1 show, respectively, the viscosities and densities of the studied chloroaluminate ionic liquids, which have not been reported to date. For both studied ionic liquids, a decrease of viscosity and density with increase of temperature is observed. $\left[\mathrm{Ph}-\mathrm{C}_{2} \mathrm{mim}\right]\left[\mathrm{AlCl}_{4}\right]$ is found to be more viscous, but less dense than [Bzlmim][ $\left.\mathrm{AlCl}_{4}\right]$. The smaller density of the ionic liquid enables the better dispersion in the hexane phase, and in consequence, the better access of monomer to the active centre. This is probably a reason, while application of the

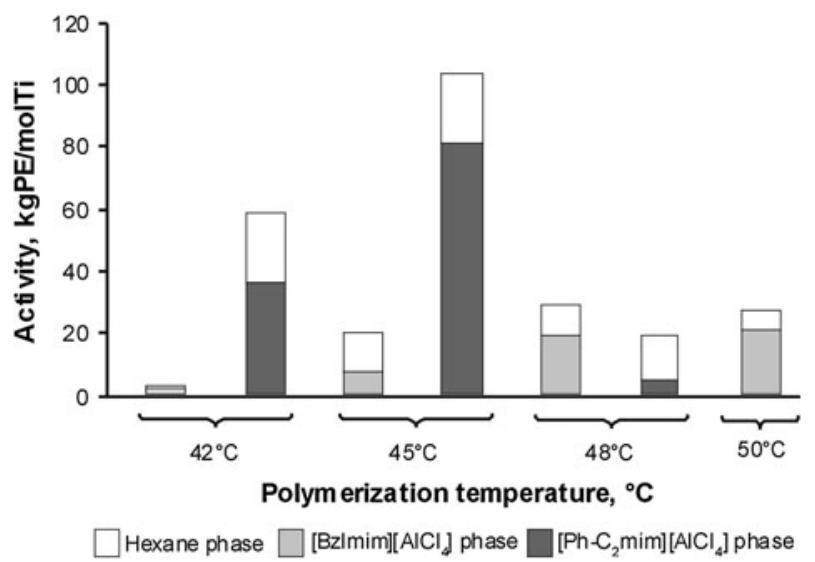

Fig. 2 Influence of the kind of the ionic liquid and the reaction temperature on the biphasic ethylene polymerization using the $\mathrm{Cp}_{2} \mathrm{TiCl}_{2}$ catalyst and the $\mathrm{AlEtCl}_{2}$ compound. Polymerization conditions: $\mathrm{AlEtCl}_{2} / \mathrm{Cp}_{2} \mathrm{TiCl}_{2}$ molar ratio $=133, t=60 \mathrm{~min}$ 


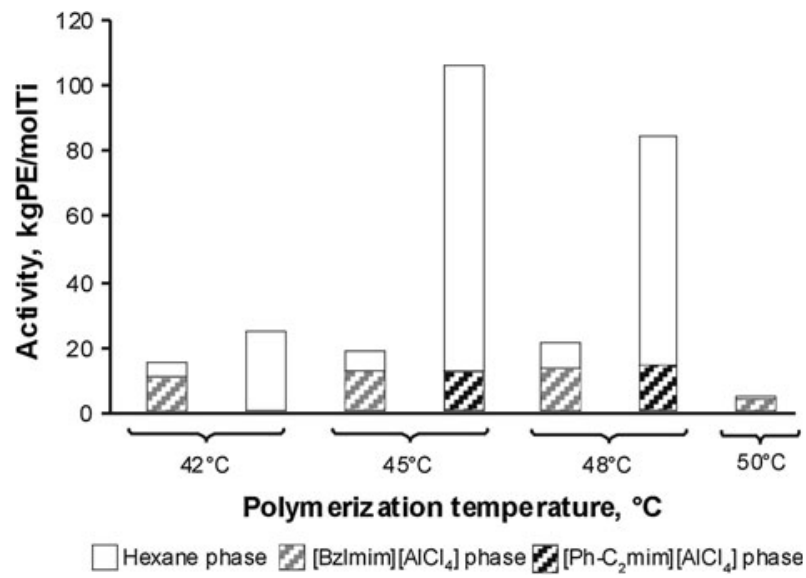

Fig. 3 Influence of the kind of the ionic liquid and the reaction temperature on the biphasic ethylene polymerization using the $\mathrm{Cp}_{2} \mathrm{TiCl}_{2}$ catalyst and the $\mathrm{AlEt}_{2} \mathrm{Cl}$ compound. Polymerization conditions: $\mathrm{AlEt}_{2} \mathrm{Cl} / \mathrm{Cp}_{2} \mathrm{TiCl}_{2}$ molar ratio $=133, t=60 \mathrm{~min}$

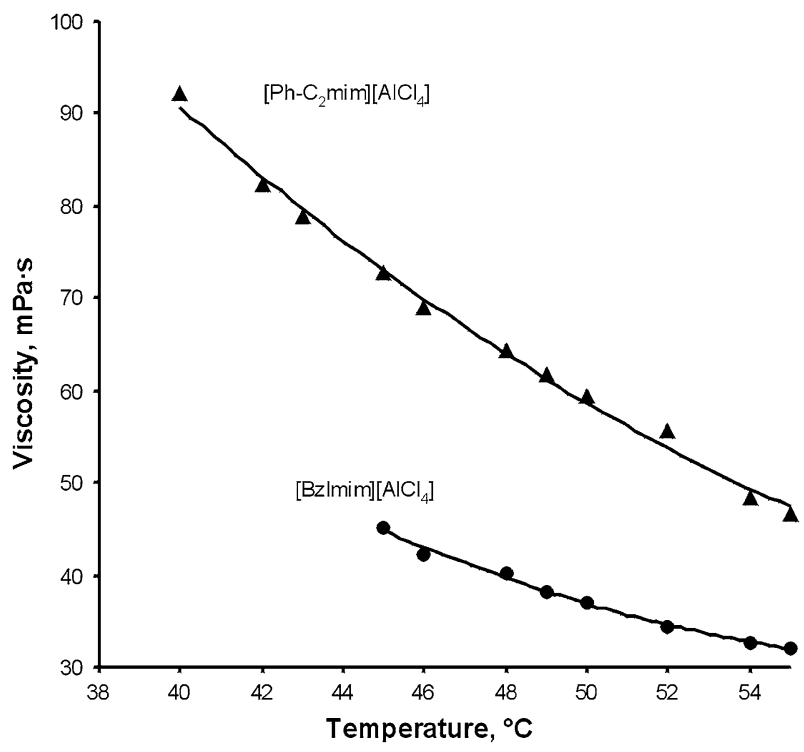

Fig. 4 Viscosities of the studied aralkyl ionic liquids

$\left[\mathrm{Ph}-\mathrm{C}_{2} \mathrm{mim}\right]\left[\mathrm{AlCl}_{4}\right]$ ionic liquid resulted in higher catalyst activity of the biphasic ethylene polymerization than when $[\mathrm{Bzlmim}]\left[\mathrm{AlCl}_{4}\right]$ was applied.

The amount of product transferred to the hexane phase depends also on the type and the amount of alkylaluminium compound used. In general, when $\mathrm{AlEtCl}_{2}$ is applied, the majority of the polyethylene product remains in the ionic liquid phase (Fig. 2). In contrast, application of $\mathrm{AlEt}_{2} \mathrm{Cl}$ significantly improves the polymerization performed in $\left[\mathrm{Ph}-\mathrm{C}_{2} \mathrm{mim}\right]\left[\mathrm{AlCl}_{4}\right]$ (Fig. 3), for which the majority of the 
Table 1 Densities of the studied aralkyl ionic liquids

\begin{tabular}{lll}
\hline Ionic liquid & $T\left({ }^{\circ} \mathrm{C}\right)$ & Density $\left(\mathrm{g} / \mathrm{cm}^{3}\right)$ \\
\hline$\left[\mathrm{Ph}-\mathrm{C}_{2} \mathrm{mim}\right]\left[\mathrm{AlCl}_{4}\right]$ & 40 & 1.2588 \\
& 42 & 1.2581 \\
& 45 & 1.2575 \\
& 48 & 1.2569 \\
{$[\mathrm{Bzlmim}]\left[\mathrm{AlCl}_{4}\right]$} & 50 & 1.2564 \\
& 40 & 1.3495 \\
& 42 & 1.3490 \\
& 45 & 1.3486 \\
& 48 & 1.3483 \\
& 50 & 1.3480 \\
\hline
\end{tabular}

polyethylene is transported to the hexane phase. Interestingly, in the case of $\left[\right.$ Bzlmim] $\left[\mathrm{AlCl}_{4}\right]$ such an effect does not occur. The effect of the kind of alkylaluminium compound used as well as its concentration, described in the form of the activator/catalyst molar ratio (67-200), on the polymerization carried out in $\left[\mathrm{Ph}-\mathrm{C}_{2} \mathrm{mim}\right]\left[\mathrm{AlCl}_{4}\right]$ at the optimal temperature $45{ }^{\circ} \mathrm{C}$ is presented in Fig. 5. When $\mathrm{AlEtCl}_{2}$ is applied, an increase in the catalyst activity is observed up to the $\mathrm{AlEtCl}_{2}$ / $\mathrm{Cp}_{2} \mathrm{TiCl}_{2}$ molar ratio value 167 , when the highest catalyst activity is obtained $(180 \mathrm{~kg} \mathrm{PE} /(\mathrm{mol} \mathrm{Ti} \times \mathrm{h}))$. Unfortunately, the majority of the product remains in the ionic liquid phase. When $\mathrm{AlEt}_{2} \mathrm{Cl}$ is applied, the catalyst activity is generally lower except when the $\mathrm{AlEt}_{2} \mathrm{Cl} / \mathrm{Cp}_{2} \mathrm{TiCl}_{2}$ molar ratio value is 133 , for which a similar catalyst activity was obtained for both alkylaluminium compounds (105 kg PE/(mol $\mathrm{Ti} \times \mathrm{h})$ ). As can be seen, an increase in the amount of the alkylaluminium compound results in an increase of the total catalyst activity, but only to some extent. This has also been reported for both olefin polymerization and oligomerization in the ionic liquid media [45-47]. It should be noticed that $\mathrm{AlEt}_{2} \mathrm{Cl}$ is better for the biphasic process because the majority of the product is transported to the hexane phase. In the case of analogous biphasic ethylene, polymerization performed using 1- $n$-alkyl-3-methylimidazolium and 1- $n$-alkyl-4-methylpyridinium chloroaluminate ionic liquids; application of $\mathrm{AlEt}_{2} \mathrm{Cl}$ improves transfer of the polymer product to the hexane phase. However, in similar conditions, the activity of the catalytic system was considerably lower than and does not exceed $45 \mathrm{~kg} \mathrm{PE} /(\mathrm{mol}$ $\mathrm{Ti} \times \mathrm{h})[30,32]$.

In order to show the effect of the ionic liquid on the catalyst activity, the monophasic (homogeneous) polymerization was performed at the same reaction conditions. In the case of $\mathrm{AlEtCl}_{2}$, the range of the concentration applied $\left(2.0-6.0 \times 10^{-3} \mathrm{~mol}\right)$ was found to be insufficient to carry out the polymerization reaction for the homogeneous system. When $\mathrm{AlEt}_{2} \mathrm{Cl}$ was applied as the activator of the $\mathrm{Cp}_{2} \mathrm{TiCl}_{2}$ catalyst, much smaller PE amounts was obtained than in the case of the biphasic systems. For example, at the activator concentration $4 \times 10^{-3} \mathrm{~mol}$, $53.9 \mathrm{~kg} \mathrm{PE} /(\mathrm{mol} \mathrm{Ti} \times \mathrm{h})$ was obtained, which equals $50 \%$ of the total polymerization field obtained in the biphasic system with the $\left[\mathrm{Ph}-\mathrm{C}_{2} \mathrm{mim}\right]\left[\mathrm{AlCl}_{4}\right]$ ionic liquid. As can be seen, the biphasic system enables to apply traditional 


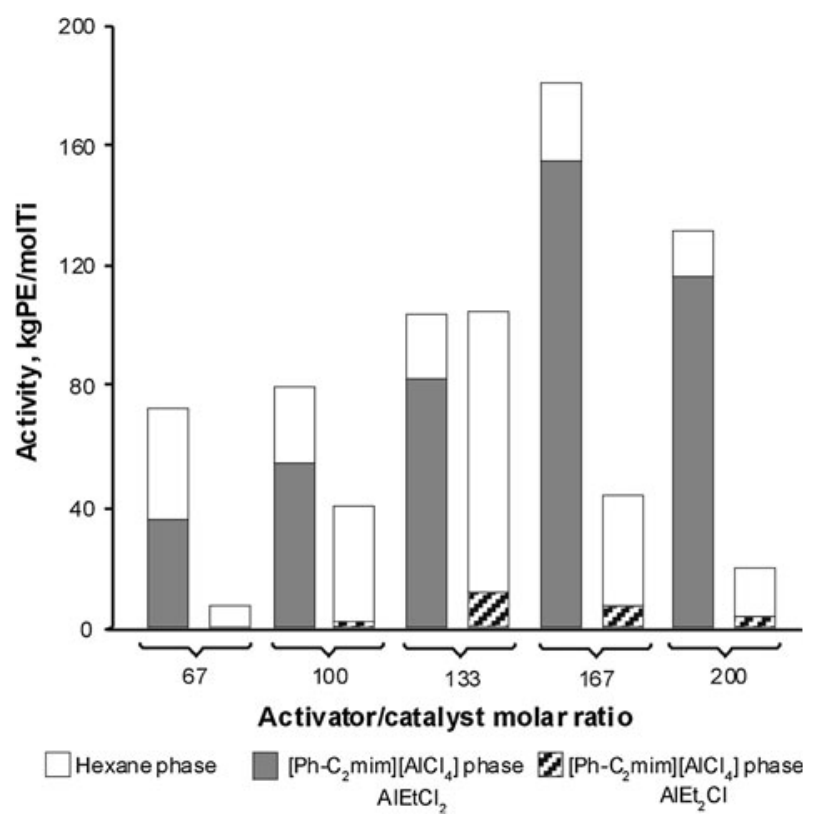

Fig. 5 Influence of the type of the alkylaluminium compound and its molar ratio to the $\mathrm{Cp}_{2} \mathrm{TiCl}_{2}$ catalyst on the biphasic ethylene polymerization using the $\left[\mathrm{Ph}-\mathrm{C}_{2} \mathrm{mim}\right]\left[\mathrm{AlCl}_{4}\right]$ ionic liquid. Polymerization conditions: $45^{\circ} \mathrm{C}, t=60 \mathrm{~min}$

alkylaluminium compounds at relatively low concentration as the activators of the titanocene catalyst for ethylene polymerization and obtain the satisfactory catalyst activities. Comparison of the results obtained using mono- and biphasic systems shows that the chloroaluminate ionic liquids are not only medium for the catalyst immobilization, but probably they also participate in the active sites creation. This results from the intrinsic characterisitic of the chloroaluminate ionic liquids, which are capable incorporating the alkylaluminium activators [47]. Therefore, the alkylaluminium compound is not only the activator, but also participates in the formation of chloroalkylaluminium anions, which influence the properties of the ionic liquid. Carlin and Wilkes [48] are correct in stating that for chloroaluminate ionic liquids, polymerization takes place only in slightly acidic conditions, which are required to create an active form from the catalyst precursor. A typical method of regulation of the acidity of the chloroaluminate ionic liquids is the application of an excess of $\mathrm{AlCl}_{3}$ so that $\mathrm{AlCl}_{3} /\left[\mathrm{C}_{\mathrm{n}} \mathrm{mim}\right] \mathrm{Cl}>0.5$. However, further increase of acidity creates a considerable amount of the $\mathrm{Al}_{2} \mathrm{Cl}_{7}{ }^{-}$anion, which produces a negative effect as the titanocene catalyst forms inactive $\mathrm{Cp}_{2} \mathrm{Ti}\left(\mathrm{AlCl}_{4}\right)_{2}$ and $\mathrm{Cp}_{2} \mathrm{TiCl}\left(\mathrm{Al}_{2} \mathrm{Cl}_{7}\right)$ complexes [48]. Similarly, application of the chloroalkylaluminium compounds influences the acidity of the chloroaluminate ionic liquids, because various anions, not only $\mathrm{AlCl}_{4}{ }^{-}, \mathrm{Al}_{2} \mathrm{Cl}_{7}{ }^{-}$, but also $\mathrm{AlEtCl}_{3}{ }^{-}, \mathrm{Al}_{2} \mathrm{EtCl}_{6}{ }^{-}$, $\mathrm{Al}_{2} \mathrm{Et}_{2} \mathrm{Cl}_{5}{ }^{-}$and $\mathrm{Al}_{3} \mathrm{EtCl}_{9}{ }^{-}$can be created $[49,50]$. The reaction conditions depend, therefore, on the kind and amount of the chloroaluminates anions present. The 
Table 2 Results of recycling of the catalyst containing ionic liquid phase in ethylene polymerization

Polymerization conditions: $\mathrm{AlEt}_{2} \mathrm{Cl} / \mathrm{Cp}_{2} \mathrm{TiCl}_{2}$ molar ratio $=133, T=45^{\circ} \mathrm{C}$, $p=5 \mathrm{~atm} ., t=60 \mathrm{~min}$ $n d$ not determined

\begin{tabular}{lll}
\hline Cycle & \multicolumn{2}{l}{ Activity $(\mathrm{kg} \mathrm{PE} /(\mathrm{mol} \mathrm{Ti} \times \mathrm{h}))$} \\
\cline { 2 - 3 } & Hexane phase & Ionic liquid phase \\
\hline First & 90 & nd \\
Second & 77 & nd \\
Third & 63 & 15 \\
Total & 230 & \\
\hline
\end{tabular}

optimal alkylaluminium concentration enables the creation of an environment where the titanium compound can be transformed to the active form but where it does not create inactive complexes.

Effects of the catalyst recycling and reaction time

Both the ionic liquids and organometallic catalysts are relatively expensive compounds. In the case of the studied biphasic systems, the efficient recycling of the ionic liquid phase is crucial for a process to be economically viable. Table 2 presents the results of the 3-cycle ethylene polymerization using the [Ph$\left.\mathrm{C}_{2} \mathrm{mim}\right]\left[\mathrm{AlCl}_{4}\right]$ ionic liquid and the $\mathrm{AlEt}_{2} \mathrm{Cl}$ activator, at the $\mathrm{Al} / \mathrm{Ti}$ molar ratio and reaction temperature optimal for this system. The greatest amount of the polyethylene was obtained in the first cycle of the polymerization. In the consecutive cycles, a decrease of the PE amounts was observed. This can be connected mainly with separation of the ionic liquid and hexane phases, which is difficult to perform properly at laboratory scale. On the other hand, possibility to apply the ionic liquid phase in consecutive reaction step indicates that the activity of the catalytic species in the ionic liquid phase is not affected by the removal of the hexane phase. The total catalyst activity of the product obtained in all cycles reaches $230 \mathrm{~kg} \mathrm{PE} /(\mathrm{mol} \mathrm{Ti} \times \mathrm{h})$. Thus, recycling of the ionic liquid phase seems to be excellent method to increase the catalyst performance. It also proves that the catalyst is fully immobilized in the ionic liquid and does not undergo the leaking to the hexane phase. The possibility to apply the ionic liquid phase in the multiple polymerization cycles indicates a considerable stability of the titanocene catalyst immobilized in the ionic liquid phase. This stability is also confirmed by an increase of the amount of the product in the reaction time (Fig. 6). Regardless of the cocatalyst applied, the increase in the reaction time results in an increase of the amount of the PE obtained, what is common for heterogeneous metallocene systems on the solid support [51-54]. It should be also noted that in the case of $\mathrm{AlEtCl}_{2}$, an increase of the $\mathrm{PE}$ amount from the ionic liquid phase was observed. In contrast, in the case of the $\mathrm{AlEt}_{2} \mathrm{Cl}$ activator, the increase of the $\mathrm{PE}$ amount takes place in the hexane phase. Long catalyst life confirmed by the increase of the amount of the polyethylene produced in the increased reaction time as well as the possible catalyst recycling can be crucial criterion for application of these biphasic systems in the large-scale continuous process. 


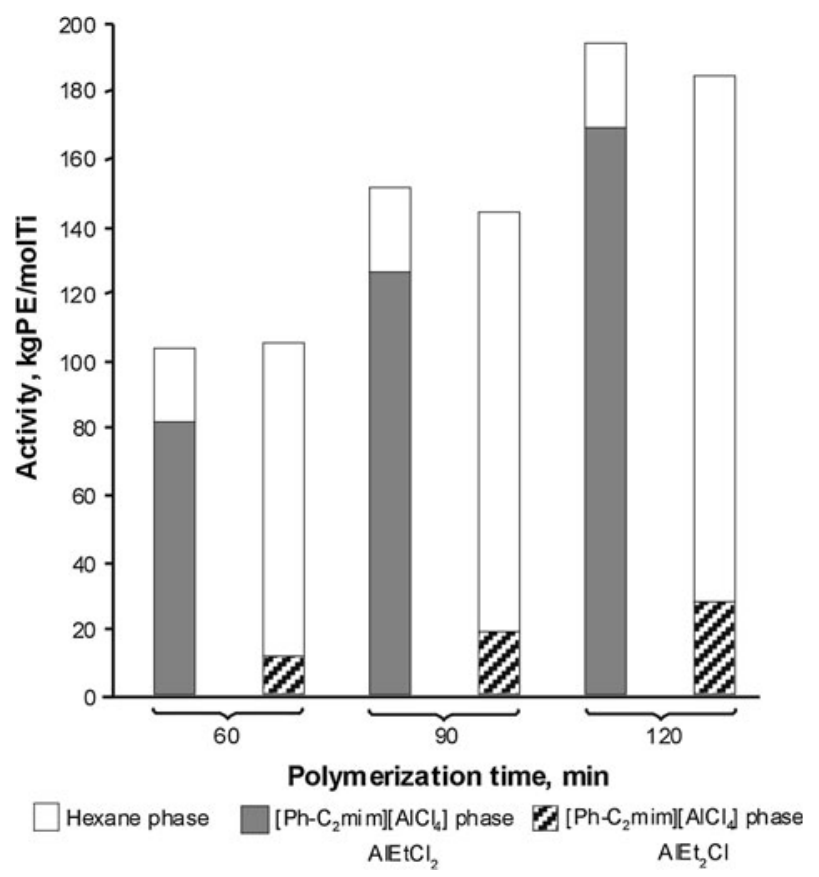

Fig. 6 Influence of the reaction time on the biphasic ethylene polymerization using the $\mathrm{Cp}_{2} \mathrm{TiCl}_{2}$ catalyst and $\mathrm{AlEtCl}_{2}$ or $\mathrm{AlEt}_{2} \mathrm{Cl}$ in the $\left[\mathrm{Ph}-\mathrm{C}_{2} \mathrm{mim}\right]\left[\mathrm{AlCl}_{4}\right]$ ionic liquid. Polymerization conditions: $45^{\circ} \mathrm{C}$ $\left(\mathrm{AlEtCl}{ }_{2}\right.$ or $\left.\mathrm{AlEt}_{2} \mathrm{Cl}\right) / \mathrm{Cp}_{2} \mathrm{TiCl}_{2}$ molar ratio $=133$

Polyethylene properties

Tables 3 and 4 present the selected properties of the polyethylene obtained using $\mathrm{AlEtCl}_{2}$ and $\mathrm{AlEt}_{2} \mathrm{Cl}$, respectively. According to the concept of biphasic polymerization, the most important product is that which is gathered in the hexane phase. For comparison, the properties of the polyethylene remained in the ionic liquid phase were also determined.

The melting temperature of the polyethylene from the hexane phase depends on both the kinds of activator used and on the ionic liquid. For $\left[\mathrm{Ph}-\mathrm{C}_{2} \mathrm{mim}\right]\left[\mathrm{AlCl}_{4}\right]$, the higher values $\left(129.7-132.2^{\circ} \mathrm{C}\right.$ ) were obtained when $\mathrm{AlEt}_{2} \mathrm{Cl}$ was used rather than $\mathrm{AlEtCl}_{2}\left(124.6-130.6^{\circ} \mathrm{C}\right)$. For $[\mathrm{Bzlmim}]\left[\mathrm{AlCl}_{4}\right]$, the melting temperatures were slightly lower $\left(<129.5^{\circ} \mathrm{C}\right)$.

The crystallinity degree has the value of $63-87 \%$. This depends mainly on the kind of ionic liquid used, and it is slightly higher when $\left[\mathrm{Ph}-\mathrm{C}_{2} \mathrm{mim}\right]\left[\mathrm{AlCl}_{4}\right]$ is used.

The bulk density depends on the kind of activator, and has the values 198-307 and $170-280 \mathrm{~g} / \mathrm{dm}^{3}$, for $\mathrm{AlEt}_{2} \mathrm{Cl}$ and $\mathrm{AlEtCl}_{2}$, respectively. An increase in the time of duration of the reaction results in an increase of the bulk density of the polyethylene. The values of the bulk densities are similar to those of the polymer obtained using metallocene catalyst anchored on solid support [6, 55]. 
Table 3 Selected properties of the $\mathrm{PE}$ samples produced using the studied ionic liquids with the $\mathrm{Cp}_{2} \mathrm{TiCl}_{2}$ catalyst and the $\mathrm{AlEtCl}{ }_{2}$ compound

\begin{tabular}{|c|c|c|c|c|c|c|c|c|c|}
\hline \multirow[t]{2}{*}{ No. } & \multirow[t]{2}{*}{ Ionic liquid } & \multirow{2}{*}{$\begin{array}{l}\mathrm{Al} / \mathrm{Ti} \\
(\mathrm{mol} / \\
\mathrm{mol})\end{array}$} & \multirow[t]{2}{*}{$T_{\mathrm{r}}\left({ }^{\circ} \mathrm{C}\right)$} & \multicolumn{6}{|c|}{ PE properties } \\
\hline & & & & $T_{\mathrm{m}}\left({ }^{\circ} \mathrm{C}\right)$ & $\begin{array}{l}\text { Crystallinity } \\
\text { degree }(\%)\end{array}$ & $\begin{array}{l}M_{w} \times 10^{-3} \\
(\mathrm{~g} / \mathrm{mol})\end{array}$ & $M_{w} / M_{n}$ & $\begin{array}{l}\text { Bulk } \\
\text { density } \\
\left(\mathrm{g} / \mathrm{dm}^{3}\right)\end{array}$ & $N^{\mathrm{a}}$ \\
\hline 1 & \multirow[t]{15}{*}[\mathrm{Ph}-\mathrm{C}_{2}\mathrm{mim}]{$\left[\mathrm{AlCl}_{4}\right]$} & 133 & 42 & 127.2 & 70.4 & 33.1 & 5.3 & 170 & 7.9 \\
\hline $2^{\mathrm{b}}$ & & 133 & 42 & 129.6 & 63.1 & 70.9 & 6.9 & 248 & 8.7 \\
\hline $3^{c}$ & & 133 & 42 & 124.5 & 65.7 & 12.3 & 4.8 & - & 6.8 \\
\hline 4 & & 67 & 45 & 130.1 & 78.1 & 74.7 & 3.6 & 255 & 9.6 \\
\hline 5 & & 100 & 45 & 129.9 & 73.0 & 60.5 & 4.1 & 214 & 7.8 \\
\hline $6^{c}$ & & 100 & 45 & 127.6 & 65.1 & 21.1 & 5.9 & 169 & 8.8 \\
\hline \multirow[t]{2}{*}{7} & & 133 & 45 & 127.6 & 85.6 & 50.5 & 4.8 & 190 & 9.8 \\
\hline & & & & & & & & & $12.55^{\mathrm{d}}$ \\
\hline \multirow[t]{2}{*}{$8^{\mathrm{b}}$} & & 133 & 45 & 130.4 & 65.6 & 68.5 & 5.4 & 243 & 8.8 \\
\hline & & & & & & & & & $9.03^{\mathrm{d}}$ \\
\hline $9^{c}$ & & 133 & 45 & 123.4 & 71.6 & 9.1 & 5.0 & 181 & 7.7 \\
\hline \multirow[t]{2}{*}{10} & & 167 & 45 & 128.9 & 87.3 & 38.1 & 4.8 & 184 & 10.8 \\
\hline & & & & & & & & & $16.92^{\mathrm{d}}$ \\
\hline 11 & & 200 & 45 & 124.6 & - & 30.9 & 4.2 & 182 & 6.9 \\
\hline 12 & & 133 & 48 & 130.6 & 82.5 & 67.0 & 8.8 & 280 & 8.7 \\
\hline 13 & \multirow[t]{6}{*}[\text{Bzlmim}]{$\left[\mathrm{AlCl}_{4}\right]$} & 133 & 42 & 124.9 & 65.9 & 17.2 & 5.5 & 164 & 6.8 \\
\hline $14^{\mathrm{c}}$ & & 133 & 42 & 124.4 & 65.8 & 13.7 & 5.2 & 176 & 6.8 \\
\hline 15 & & 133 & 45 & 129.5 & 71.0 & 39.0 & 4.7 & 223 & - \\
\hline $16^{\mathrm{c}}$ & & 133 & 45 & 122.3 & 64.4 & 11.3 & 4.3 & 161 & 7.7 \\
\hline 17 & & 133 & 48 & 126.9 & 72.5 & 65.2 & 9.3 & 248 & 5.9 \\
\hline $18^{\mathrm{c}}$ & & 133 & 48 & 123.1 & 63.4 & 10.5 & 6.9 & 185 & 7.7 \\
\hline
\end{tabular}

\footnotetext{
${ }^{a}$ Polyethylene branching, number of $\mathrm{CH}_{3}$ per $1000 \mathrm{CH}_{2}$ groups

${ }^{\mathrm{b}}$ Polymerization time $=120 \mathrm{~min}$

c Properties of polyethylene remained in the ionic liquid phase

${ }^{\mathrm{d}}$ Number of branches determined by ${ }^{1} \mathrm{H}$ NMR
}

A scanning electron micrograph (Fig. 7) demonstrates that the polyethylene produced in the biphasic mode has a shape of regular grains with diameter of about $440 \mu \mathrm{m}$. This kind of morphology is common for the polymer obtained using heterogeneous systems on solid support [54]. It should be noticed that such regular morphology was not obtained using the previously studied ionic liquids, where nonregular flake shape of polyethylene grains were obtained. The possible explanation is the nano-segregated structure of ionic liquids. The high- and low-charge density regions of the ions that compose ionic liquids tend to be segregated into a polar network and non-polar domains. The latter, depending on the relative size of the high- and low-charge regions in each ion, can exist as isolated (dispersed) islands or a second continuous phase. [56]. The non-polar regions of the aralkyl ionic liquids consist of aromatic moieties maintained by ring-stacking interactions, whereas 
Table 4 Selected properties of the PE samples produced using the studied ionic liquids with the $\mathrm{Cp}_{2} \mathrm{TiCl}_{2}$ catalyst and the $\mathrm{AlEt}_{2} \mathrm{Cl}$ compound

\begin{tabular}{|c|c|c|c|c|c|c|c|c|c|}
\hline \multirow[t]{2}{*}{ No. } & \multirow[t]{2}{*}{ Ionic liquid } & \multirow{2}{*}{$\begin{array}{l}\mathrm{Al} / \mathrm{Ti} \\
(\mathrm{mol} / \\
\mathrm{mol})\end{array}$} & \multirow[t]{2}{*}{$T_{\mathrm{r}}\left({ }^{\circ} \mathrm{C}\right)$} & \multicolumn{6}{|c|}{ PE properties } \\
\hline & & & & $T_{\mathrm{m}}\left({ }^{\circ} \mathrm{C}\right)$ & $\begin{array}{l}\text { Crystallinity } \\
\text { degree ( } \%)\end{array}$ & $\begin{array}{l}M_{w} \times 10^{-3} \\
(\mathrm{~g} / \mathrm{mol})\end{array}$ & $M_{w} / M_{n}$ & $\begin{array}{l}\text { Bulk } \\
\text { density } \\
\left(\mathrm{g} / \mathrm{dm}^{3}\right)\end{array}$ & $N^{\mathrm{a}}$ \\
\hline 1 & \multirow[t]{11}{*}[\mathrm{Ph}-\mathrm{C}_{2}\mathrm{mim}]{$\left[\mathrm{AlCl}_{4}\right]$} & 133 & 42 & 132.2 & 81.1 & 65.8 & 3.3 & 198 & 7.8 \\
\hline 2 & & 67 & 45 & 131.0 & 84.0 & 138.0 & 3.5 & - & 8.7 \\
\hline 3 & & 100 & 45 & 129.9 & 78.8 & 102.1 & 4.0 & 231 & 7.7 \\
\hline \multirow[t]{2}{*}{4} & & 133 & 45 & 129.7 & 83.6 & 71.0 & 4.2 & 252 & 7.8 \\
\hline & & & & & & & & & $8.36^{\mathrm{d}}$ \\
\hline $5^{\mathrm{b}}$ & & 133 & 45 & 130.6 & 62.6 & 98.8 & 4.5 & 307 & 8.7 \\
\hline $6^{\mathrm{c}}$ & & 133 & 45 & 128.9 & 61.0 & 63.6 & 9.2 & - & 6.8 \\
\hline \multirow[t]{2}{*}{7} & & 167 & 45 & 130.8 & 84.0 & 64.5 & 4.6 & 242 & 6.8 \\
\hline & & & & & & & & & $8.36^{\mathrm{d}}$ \\
\hline 8 & & 200 & 45 & 130.2 & 73.8 & 59.1 & 5.4 & 259 & 7.9 \\
\hline 9 & & 133 & 48 & 130.3 & 86.5 & 83.4 & 4.1 & 416 & 7.8 \\
\hline 10 & {$[\mathrm{Bzlmim}]\left[\mathrm{AlCl}_{4}\right]$} & 133 & 48 & 128.9 & - & 59.9 & 4.3 & 253 & 5.8 \\
\hline
\end{tabular}

\footnotetext{
${ }^{\text {a }}$ Polyethylene branching, number of $\mathrm{CH}_{3}$ per $1000 \mathrm{CH}_{2}$ groups

${ }^{\mathrm{b}}$ Polymerization time $=120 \mathrm{~min}$

${ }^{c}$ Properties of polyethylene remained in the ionic liquid phase

${ }^{d}$ Number of branches determined by ${ }^{1} \mathrm{H}$ NMR
}

similar region in the analogous alkyl ionic liquids consist of alkyl chains maintained by non-polar van der Waals interactions common for polyethylene. Thus, the created polyethylene chain cannot interact much effectively with non-polar regions of the aralkyl ionic liquids as in the case of the alkyl analogues. In consequence, the polyethylene chain is packed by surrounding polar environment in regular spherical shape to minimize the surface of contact.

The molecular weight is higher when $\left[\mathrm{Ph}-\mathrm{C}_{2} \mathrm{mim}\right]\left[\mathrm{AlCl}_{4}\right]$ is applied $\left(33,100<M_{w}>138,000 \mathrm{~g} / \mathrm{mol}\right)$ rather than [Bzlmim] $\left[\mathrm{AlCl}_{4}\right]\left(17,200<M_{w}>65,200\right.$ $\mathrm{g} / \mathrm{mol})$. It is also higher when $\mathrm{AlEt}_{2} \mathrm{Cl}$ is used instead of $\mathrm{AlEtCl}_{2}$. It decreases, however, with the increase of the activator/catalyst molar ratio, regardless of the activator used. An increase in the time of duration of the reaction results in an increase of the molecular weight of the polyethylene. This is common for polymer products obtained using organometallic catalysts [52].

The molecular weight distribution $\left(M_{w} / M_{n}=3.3-3.8\right)$ is monomodal. It is broader for the system with $\mathrm{AlEtCl}_{2}$ (4.1-9.3) than for that with $\mathrm{AlEt}_{2} \mathrm{Cl}$ (3.3-5.4). It is also broader than that of the polyethylene produced using homogeneous metallocene systems. However, it is similar to those obtained using the titanocene catalyst anchored on the solid support [6, 44].

Regardless of the polymerization conditions, the number of branches $\left(5-10 \mathrm{CH}_{3}\right.$ groups per $1000 \mathrm{CH}_{2}$ groups) indicated the linear character of the obtained polyethylene. 

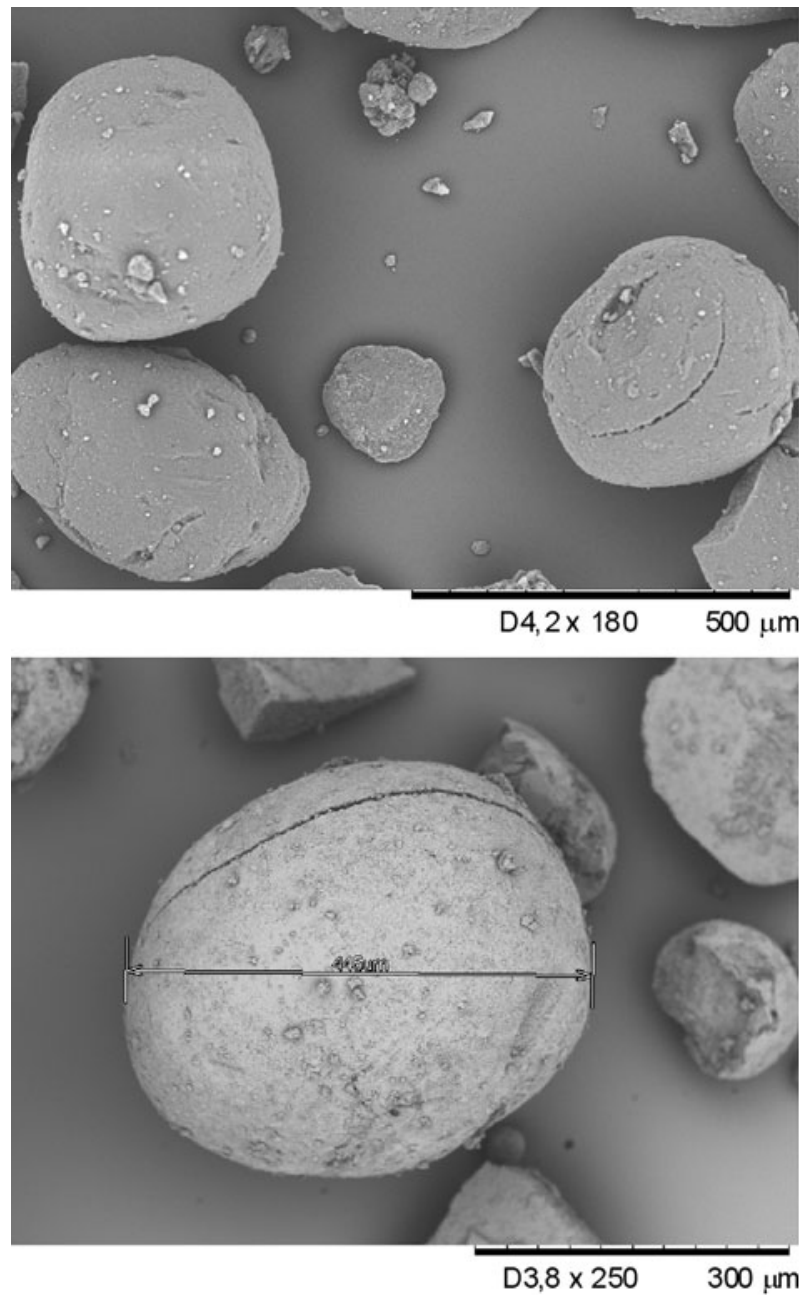

Fig. 7 SEM images of the PE samples obtained in the biphasic polymerization

Interestingly, the polyethylene obtained using 1-n-alkyl-3-methylimidazolium or 1-n-alkyl-4-methylpyridinium chloroaluminates and $\mathrm{AlEt}_{2} \mathrm{Cl}$ always was characterized by lower melting temperature, crystallinity, molecular weight, bulk density than that obtained using $\mathrm{AlEtCl}_{2}[30,32]$. In contrast, the opposed effect of the kind of alkylaluminium activator on the properties of polyethylene was observed in the case of $\left[\mathrm{Ph}-\mathrm{C}_{2} \mathrm{mim}\right]\left[\mathrm{AlCl}_{4}\right]$.

The properties of the polyethylene remained in the ionic liquid, regardless of the kind of the ionic liquid and alkylaluminium activator, are similar to those of the polymer gathered form the hexane phase. Only the molecular weights of the polyethylene from the ionic liquid phase are considerably lower. They decrease with the increase of the amount of the activator, as in the case of the PE from hexane phase. 

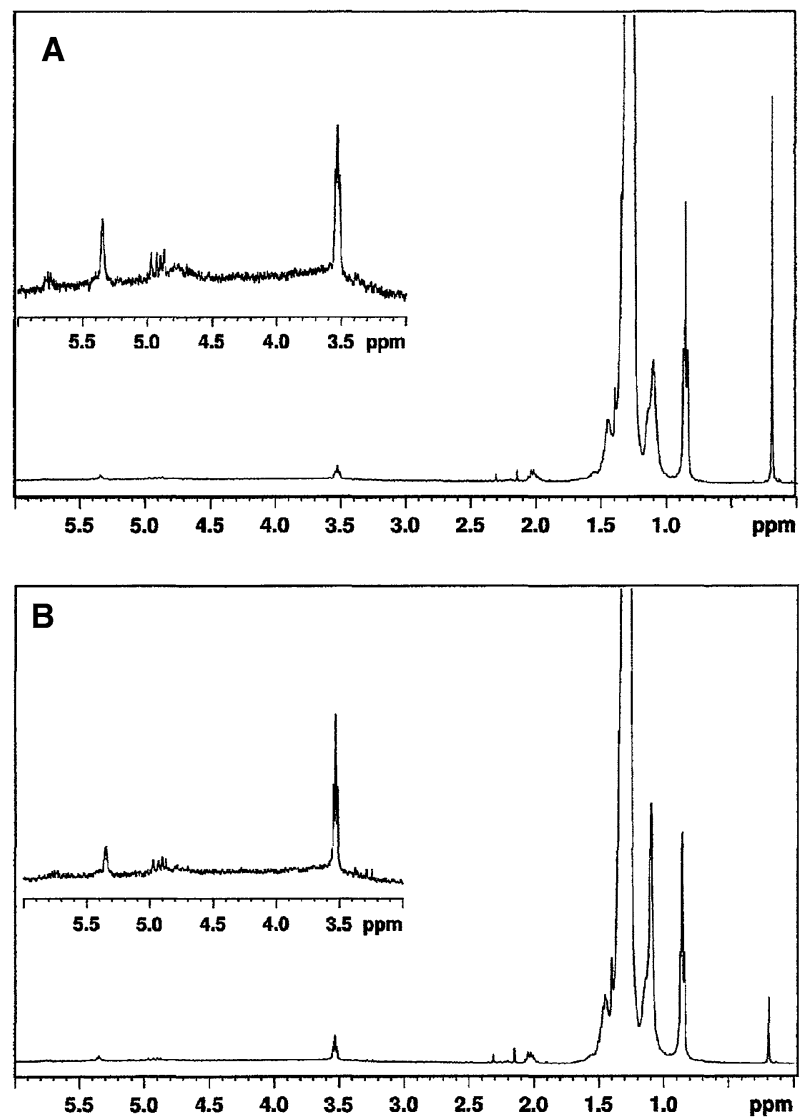

Fig. $8{ }^{1} \mathrm{H}$ NMR spectra of the polyethylene obtained in the biphasic polymerization with the $\mathrm{Cp}_{2} \mathrm{TiCl}_{2}$ catalyst activated by $\mathrm{AlEt}_{2} \mathrm{Cl}$ at: $\mathbf{a} \mathrm{AlEt}_{2} \mathrm{Cl} / \mathrm{Cp}_{2} \mathrm{TiCl}_{2}$ molar ratio $=133$, b $\mathrm{AlEt}_{2} \mathrm{Cl} / \mathrm{Cp}_{2} \mathrm{TiCl}_{2}=167$

To explain this dependence, the kind of the terminal groups in the polymer chain was determined using ${ }^{1} \mathrm{H}$ NMR and FT-IR methods. Figure 8 presents the ${ }^{1} \mathrm{H}$ NMR spectra of the PE samples obtained in the biphasic process. Apart of the strong signal about $1.30 \mathrm{ppm}$ ascribed to methylene groups $\left(-\mathrm{CH}_{2}-\right)$, the much weaker signals are seen, resulting from the presence of vinyl groups (4.87-4.97 and 5.75-5.77 ppm), allylic methylene groups (2.01-2.06 ppm) and methyl groups $(0.85 \mathrm{ppm})$. The signal at $3.53 \mathrm{ppm}$ results from the presence of hydroxyl groups $(-\mathrm{OH})$ in the polymer chain. This indicates that the alkylaluminium compound also participates in the termination reaction of the polymer chain [57, 58]. Furthermore, intensity of this signal increases with the increase of the alkylaluminium activator concentration, which proves occurrence of this termination mechanism.

The participation of the alkylaluminium compound in the termination reaction of the polymer chain explains the observed decrease of the PE molecular weight with the increase of the $\mathrm{AlEtCl}_{2}$ and $\mathrm{AlEt}_{2} \mathrm{Cl}$ concentrations. It should be noted that chain termination via chain transfer to aluminium is usually of minor importance in olefin 
polymerization with metallocene catalysts, where the termination reaction of the polymer chain occurs mainly by $\beta$-H transfer $[59,60]$.

\section{Conclusions}

The chloroaluminates ionic liquids, $\left[\mathrm{Ph}-\mathrm{C}_{2} \mathrm{mim}\right]\left[\mathrm{AlCl}_{4}\right]$ or $[\mathrm{Bzlmim}]\left[\mathrm{AlCl}_{4}\right]$, with the aralkyl substituent at the imidazolium cation, were applied to biphasic ethylene polymerization as media for the $\mathrm{Cp}_{2} \mathrm{TiCl}_{2}$ catalyst and $\mathrm{AlEtCl}_{2}$ or $\mathrm{AlEt}_{2} \mathrm{Cl}$ alkylaluminium compounds. This kind of the ionic liquids has not been investigated to date in the polymerization reactions. The amount of the polyethylene product obtained in this biphasic process depends on the type of ionic liquid, the type and amount of the alkylaluminium compound, the temperature and the time of the reaction. The ionic liquid with 2-phenylethyl substituent, $\left[\mathrm{Ph}-\mathrm{C}_{2} \mathrm{mim}\right]\left[\mathrm{AlCl}_{4}\right]$, was found to be much more suitable to immobilize the titanocene catalyst in the performed polyreaction than [Bzlmim] $\left[\mathrm{AlCl}_{4}\right]$ with benzyl substituent. Application of the $\left[\mathrm{Ph}-\mathrm{C}_{2} \mathrm{mim}\right]\left[\mathrm{AlCl}_{4}\right]$ ionic liquid and $\mathrm{AlEt}_{2} \mathrm{Cl}$ activator enabled to obtain satisfactory polyethylene amounts, which was gathered mainly in the hexane phase. In this ionic liquid melt, increase in the reaction time results in considerable increase of the amount of polyethylene and improves the PE transfer from the ionic liquid to the hexane phase. It confirms the stability of the titanocene catalyst immobilized in the studied ionic liquid media. The catalyst stability was also proved by the reuse of the ionic liquid phase containing the catalyst in the consecutive polymerization reactions. The catalyst is also stable in higher temperatures than in the case of analogous 1 - $n$-alkylimidazolium ionic liquids.

It should be noted that application of the biphasic systems with the [Ph$\left.\mathrm{C}_{2} \mathrm{mim}\right]\left[\mathrm{AlCl}_{4}\right]$ ionic liquid, in the range of the alkylaluminium activators concentration used, enabled to obtain higher catalyst activities as compared to those of the homogeneous analogues. This indicates that the chloroaluminate ionic liquids possibly participate in the creation of the active sites.

The kind of the aralkyl ionic liquid as well as the reaction parameters influence the properties of the polyethylene produced. The $\left[\mathrm{Ph}-\mathrm{C}_{2} \mathrm{mim}\right]\left[\mathrm{AlCl}_{4}\right]$ ionic liquid, as a medium of the $\mathrm{Cp}_{2} \mathrm{TiCl}_{2}$ catalyst and $\mathrm{AlEt}_{2} \mathrm{Cl}$ activator, enables to obtain polyethylene characterized by the properties such as the bulk density and polymer particles morphology, typical for the polymer produced using metallocene catalyst supported on a solid carrier. The regular shape of the polymer particles should be mentioned, which results probably from the ring-stacking interactions in non-polar regions of the aralkyl ionic liquid. The observed decrease of the PE molecular weight with the increase of the activator concentration results from the fact that the alkylaluminium activator participates in the termination reaction of the polymer chain. This is rather uncommon for the polymerization using metallocene catalysts.

The presented result indicates that the immobilization of the metallocene catalyst in the ionic liquid media can be a novel alternative to the catalyst heterogenization on a solid carrier. 
Acknowledgments The work was supported by a grant from the Polish Ministry of Science and Higher Education No N N209 335337. Katarzyna Dziubek is a recipient of Ph.D. fellowship from a project funded by the European Social Fund.

Open Access This article is distributed under the terms of the Creative Commons Attribution License which permits any use, distribution, and reproduction in any medium, provided the original author(s) and the source are credited.

\section{References}

1. Natta G, Pino P, Mazzanti G, Giannini U (1957) A crystallizable organometallic complex containing titanium and aluminium. J Am Chem Soc 79:2975-2976. doi:10.1021/ja01568a083

2. Breslow DS, Newburg NR (1957) Bis-(cyclopentadienym)-titanium dichloride-alkylaluminium complexls as catalyst for the polymerization of ethylene. J Am Chem Soc 79:5072-5073. doi: $10.1021 / \mathrm{ja} 01575 \mathrm{a} 066$

3. Sinn H, Kaminsky W, Vollmer HJ, Woldt R (1980) "Living Polymers" on Polymerization with Extremely Productive Ziegler Catalysts. Angew Chem 19:390-392. doi:10.1002/anie.198003901

4. Kaminsky W (2004) The discovery of metallocene catalysts and their present state of the art. J Polym Sci A Polym Chem 42:3911-3921. doi:10.1002/pola.20292

5. Kaminsky W (1998) Highly active metallocene catalysts for olefin polymerization. J Chem Soc Dalton Trans 1413-1418. doi:10.1039/A800056E

6. Hlatky GG (2000) Heterogeneous single-site catalysis for olefin polymerization. Chem Rev 100:1347-1376. doi:10.1021/cr9902401

7. Severn JR, Chadwick JC, Duchateau R, Friederichs N (2005) "Bound but not gagged"-immobilizing single-site $\alpha$-olefin polymerization catalysis. Chem Rev 105:4073-4147. doi:10.1021/cr040 $670 \mathrm{~d}$

8. Jezequel M, Dufaud V, Ruiz-Garcia MJ, Carrillo-Hermosilla F, Neugebauer U, Niccolai GP, Lefebvre F, Bayard F, Corker J, Fiddy S, Evans J, Broyer J-P, Malinge J, Basset J-M (2001) Supported metallocene catalysts by surface organometallic chemistry, synthesis, characterization, and reactivity in ethylene polymerization of oxide-supported mono- and biscyclopentadienyl zirconium alkyl complexes: establishment of structure/reactivity relationships. J Am Chem Soc 123: 3520-3540. doi:10.1021/ja000682q

9. Chien JCW (1999) Supported metallocene polymerization catalysis. Top Catal 7:23-36. doi: 10.1023/A:1019111700284

10. Joó F, Papp E, Kathó A (1998) Molecular catalysis in liquid multiphase systems. Top Catal 5:113-124. doi:10.1023/A:1019193701676

11. Dupont J, de Souza RF, Suarez PAZ (2002) Ionic liquid (molten salt) phase organometallic catalysis. Chem Rev 102:3667-3692. doi:10.1021/cr010338r

12. Wasserscheid P (2007) Continuous reaction using ionic liquids as catalytic phase. J Ind Eng Chem $13: 325-338$

13. Olivier-Bourbigou H, Magna L (2002) Ionic liquids: perspectives for organic reactions. J Mol Catal A Chem 182-183:419-437. doi:10.1016/S1381-1169(01),00465-4

14. Olivier-Bourbigou H, Magna L, Morvan D (2010) Ionic liquids and catalysis: recent progress from knowledge to applications. Appl Catal A Gen 373:1-56. doi:10.1016/j.apcata.2009.10.008

15. Zhang S, Sun N, He X, Lu X, Zhang X (2006) Physical properties of ionic liquids: database and evaluation. J Phys Chem Ref Data 35:1475-1517. doi:10.1063/1.2204959

16. Holbrey JD, Rogers RD (2008) Physicochemical properties of ionic liquids: melting points and phase diagrams. In: Wasserscheid P, Welton T (eds) Ionic liquids in synthesis, 2nd edn. Wiley, Weinheim, pp 57-72

17. Chiappe C, Pieraccini D (2005) Ionic liquids: solvent properties and organic reactivity. J Phys Org Chem 18:275-297. doi:10.1002/poc.863

18. Huddleston JG, Visser AE, Reichert WM, Willauer HD, Broker GA, Rogers RD (2001) Characterization and comparison of hydrophilic and hydrophobic room temperature ionic liquids incorporating the imidazolium cation. Green Chem 3:156-164. doi:10.1039/b103275p

19. Mantz RA, Trulove PC (2008) Viscosity and density of ionic liquids. In: Wasserscheid P, Welton T (eds) Ionic liquids in synthesis, 2nd edn. Wiley, Weinheim, pp 72-88 
20. Lee S (2006) Functionalized imidazolium salts for task-specific ionic liquids and their applications. Chem Commun 1049-1063. doi:10.1039/b514140k

21. Davis JH (2004) Task-specific ionic liquids. Chem Lett 33:1072-1077. doi:10.1246/cl.2004.1072

22. Fei Z, Geldbach TJ, Zhao D, Dyson PJ (2006) From dysfunction to bis-function: on the design and applications of functionalised ionic liquids. Chem Eur J 12:2122-2130. doi:10.1002/chem.2005 00581

23. Jain N, Kumar A, Chauhan S, Chauhan SMS (2005) Chemical and biochemical transformations in ionic liquids. Tetrahedron 61:1015-1060. doi:10.1016/j.tet.2004.10.070

24. Chowdhury S, Mohan RS, Scott JL (2007) Reactivity of ionic liquids. Tetrahedron 63:2363-2389. doi:10.1016/j.tet.2006.11.001

25. Zhao D, Wu M, Kou Y, Min E (2002) Ionic liquids: application in catalysis. Catal Today 74:157-189. doi:10.1016/S0920-5861(01),00541-7

26. Kubisa P (2009) Ionic liquids as a solvents for polymerization processes-Progress and challenges. Prog Polym Sci 34:1333-1347. doi:10.1016/j.progpolymsci.2009.09.001

27. Meyer C, Wasserscheid P (2010) Effective $n$-octane isomerization under exceptionally mild conditions using a novel class of superacidic ionic liquids. Chem Commun 46:7625-7627. doi: 10.1039/C0CC02293D

28. Ochędzan-Sodłak W, Sacher-Majewska B (2007) Biphasic ethylene polymerization using ionic liquid over a titanocene catalyst activated by an alkyl aluminium compound. Eur Polym J 43:3688-3694. doi:10.1016/j.eurpolymj.2007.05.034

29. Ochędzan-Siodłak W, Pawelska P (2008) Chloroaluminate ionic liquids as a medium of titanocene catalyst activated by alkyl aluminum compounds for ethylene polymerization. Polimery (Warsaw) 53:371-376

30. Ochędzan-Siodłak W, Dziubek K, Siodłak D (2008) Biphasic ethylene polymerisation using 1- $n$ alkyl-3-methylimidazolium tetrachloroaluminate ionic liquid as a medium of the $\mathrm{Cp}_{2} \mathrm{TiCl}_{2}$ titanocene catalyst. Eur Polym J 44:3608-3614. doi:10.1016/j.eurpolymj.2008.08.037

31. Ochędzan-Siodłak W, Dziubek K, Czaja K (2009) Comparison of imidazolium and pyridinium ionic liquids as a the media for biphasic ethylene polymerization in the presence of titanocene catalyst. Polimery (Warsaw) 54:501-506

32. Ochędzan-Siodłak W (2011) Ionic liquids in biphasic ethylene polymerization. In: Kokorin A (ed) Ionic liquids: applications and perspectives. Intech, Rijeka, pp 29-44

33. Yue C, Fang D, Yi T-F (2011) Synthesis and application of task-specific ionic liquids used as catalysts and/or solvents in organic unit reactions. J Mol Liq 163:99-121. doi:10.1016/j.molliq.2011. 09.001

34. Tang S, Baker GA, Zhao H (2012) Ether- and alcohol-functionalized task-specific ionic liquids: attractive properties and applications. Chem Soc Rev 41:4030-4066. doi:10.1039/c2cs15362a

35. Kaminsky W (1996) New polyolefins by metallocene catalysts. Macromol Chem Phys 197:39073945. doi:10.1002/macp.1996.021971201

36. Kaminsky W (2012) Discovery of methylaluminoxane as cocatalyst for olefin polymerization. Macromolecules 45:3289-3297. doi:10.102/ma202453u

37. Dötterl M, Alt HG (2012) Buffered aluminum chloride as a highly efficient cocatalyst for olefin dimerization and polymerization. ChemCatChem 4(3):370-378. doi:10.1002/cctc.201100388

38. Muldoon MJ (2010) Modern multiphase catalysis: new developments in the separation of homogeneous catalysts. Dalton Trans 39:337-348. doi:10.1039/b916861n

39. Bara JE, Carlisle TK, Gabriel ChJ, Camper D, Finotello A, Gin DL, Noble RD (2009) Guide to $\mathrm{CO}_{2}$ separation in imidazolium-based room-temperature ionic liquids. Ind Eng Chem Res 48:2739-2751. doi:10.1021/ie8016237

40. Mahurin SM, Dai T, Yeary JS, Luo H, Dai S (2011) Benzyl-functionalized room temperature ionic liquids for $\mathrm{CO}_{2} / \mathrm{N}_{2}$ separation. Ind Eng Chem Res 50:14061-14069. doi:10.1021/ie201428k

41. Mehnert CP (2005) Supported ionic liquid catalysis. Chem Eur J 11:50-56. doi:10.1002/chem.2004 00683

42. Valkenberg MH, deCastro C, Hölderich WF (2001) Immoblisation of chloroaluminate ionic liquids on silica materials. Top Catal 14:139-144. doi:10.1023/A:1009023520210

43. Sarma SS, Sivaram S (1997) Magnesium chloride supported bis(cyclopentadienyl)titanium(IV) chloride-MAO catalyst for ethylene polymerization. Macromol Chem Phys 198:495-503. doi: 10.1002/macp.1997.021980222

44. Kaminsky W, Müller F, Sperber O (2005) Comparison of olefin polymerization processes with metallocene catalysts. Macromol Mater Eng 290:347-352. doi:10.1002/mame.200400285 
45. de Souza RF, Leal BC, de Souza MO, Thiele D (2007) Nickel-catalyzed propylene dimerization in organochloroaluminate ionic liquids: control of the isomerization reaction. J Mol Catal A Chem 272:6-10. doi:10.1016/j.molcata.2007.03.003

46. Pei L, Liu X, Gao H, Wu Q (2009) Biphasic oligomerization of ethylene with nickel complexes immobilized in organochloroaluminate ionic liquids. Appl Organomet Chem 23:455-459. doi: 10.1002/aoc. 1542

47. Thiele D, de Souza RF (2011) Biphasic ethylene oligomerization using bis(imino)pyridine cobalt complexes in methyl-butylimidazolium organochloroaluminate ionic liquids. J Mol Catal A Chem 340:83-88. doi:10.1016/j.molcata.2011.03.015

48. Carlin RT, Wilkes JS (1990) Complexation of $\mathrm{Cp}_{2} \mathrm{MCl}_{2}$ in cloroaluminate molten salt: relevance to homogenous Ziegler-Natta catalysis. J Mol Catal 63:125-129. doi:10.1016/0304-5102(90)85135-5

49. Chauvin Y, Einloft S, Olivier H (1995) Catalytic dimerization of propylene by nickel-phosphine complexes in 1-butyl-3-methylimidazolium chloride/ $\mathrm{AlEt}_{x} \mathrm{Cl}_{3-x}(x=0,1)$ ionic liquids. Ind Eng Chem Res 34:1149-1155. doi:10.1021/ie00043a017

50. Thiele D, de Souza RF (2007) The role of aluminum species in biphasic butene dimerization catalyzed by nickel complexes. J Mol Catal A Chem 264:293-298. doi:10.1016/j.molcata.2006.09.026

51. Kaminsky W, Winkelbach H (1999) Influence of supported metallocene catalysts on polymer tacicity. Top Catal 7:61-67. doi:10.1023/A:1019124103010

52. Ochędzan-Siodłak W, Nowakowska M (2005) Heterogeneous zirconocene catalyst on magnesium support $\mathrm{MgCl}_{2}(\mathrm{THF})_{2}$ modified by $\mathrm{AlEt}_{2} \mathrm{Cl}$ for ethylene polymerization. Eur Polym J 41:941-947. doi:10.1016/eurpolymj.2004.11.021

53. de Freitas JD, dos Santos JHZ, Meneghetti SMP, Meneghetti MR (2011) Polymerization of ethylene: some aspects of metallocene catalyst stabilization under homogeneous and heterogeneous reaction conditions. J Appl Polym Sci 119:3051-3057. doi:10.1002/app.33058

54. Huang R, Duchateau R, Koning CE, Chadwick JC (2008) Zirconocene immobilization and activation on $\mathrm{MgCl}_{2}$-based supports: factors affecting ethylene polymerization activity. Macromolecules 41:579-590. doi:10.1021/ma7024557

55. Lin Ch-H (2000) Control of polymer particle size by supported metallocene catalysis. Catal Lett 68:63-65. doi:10.1023/A:1019019000611

56. Shimizu K, Gomes MFC, Pádua AAH, Rebelo LPN, Lopes JNC (2010) Three commentaries on the nano-segregated structure of ionic liquids. J Mol Struct Theochem 946:70-76. doi:10.1016/ j.theochem.2009.11.034

57. Liu J, Stovneng JA, Rytter E (2011) Possible effect on the polyethylene chain structure of trimethylaluminum coordination to zirconocene catalysts. J Polym Sci A Polym Chem 39:3566-3577. doi:10.1002/pola.10006

58. Babu GN, Newmark RA, Chien JCW (1994) Microstructure of poly(1-hexane) produced by ansazirconocenium catalysis. Macromolecules 27:3383-3388. doi:10.1021/ma00090a037

59. Thorshaug K, Rytter E, Ystenes M (1997) Pressure effects on termination mechanisms during ethylene polymerization catalyzed by dicyclopentadienylzirconium dichloride/methylaluminoxane. Macromol Rapid Commun 18:715-722. doi:10.1002/marc.1997.030180813

60. Soga K, Uozumi T, Nakamura S, Toneri T, Teranishi T, Sano T, Arai T (1996) Structures of polyethylene and copolymers of ethylene with 1-octane and oligoethylene produced with the $\mathrm{Cp}_{2} \mathrm{ZrCl}_{2}$ and $\left[\left(\mathrm{C}_{5} \mathrm{Me}_{4}\right) \mathrm{SiMe}_{2} \mathrm{~N}(\mathrm{t}-\mathrm{Bu})\right] \mathrm{TiCl}_{2}$ catalyst. Macromol Chem Phys 197:4237-4251. doi: 10.1002/macp.1996.021971220 